\title{
Design of Commute Carpooling Based on Fixed Time and Routes
}

\author{
Guiliang Zhou, ${ }^{1,2}$ Kai Huang, ${ }^{3}$ and Lina Mao ${ }^{1,3}$ \\ ${ }^{1}$ Faculty of Transportation Engineering, Huaiyin Institute of Technology, Huaian 223003, China \\ ${ }^{2}$ School of Automotive and Traffic Engineering, Jiangsu University, Zhenjiang 212013, China \\ ${ }^{3}$ School of Transportation, Southeast University, Nanjing 210096, China \\ Correspondence should be addressed to Guiliang Zhou; zglpaper@qq.com
}

Received 8 September 2014; Revised 24 November 2014; Accepted 17 December 2014; Published 31 December 2014

Academic Editor: Per Gårder

Copyright (C) 2014 Guiliang Zhou et al. This is an open access article distributed under the Creative Commons Attribution License, which permits unrestricted use, distribution, and reproduction in any medium, provided the original work is properly cited.

\begin{abstract}
Although the private carpooling market of China has grown rapidly, it has been embarrassed by problems such as obstructed information, disordered expense, and frequent crimes currently. In this paper, a commute carpooling program based on fixed time and routes is designed and corresponding carpooling information platform is built to realize information retrieval, information matching, and mutual selection and evaluation. We have practiced the program in Huaian, China, and then evaluated it using the improved time-expense impedance model and VISSIM simulation system. The result shows that the carpooling program can reduce $65 \% \sim 86 \%$ of the time-expense impedance and optimize some network parameters up to $20 \% \sim 40 \%$. Since it will help in reducing the travel time and cost greatly, improving safety and economy during carpooling, and easing the traffic congestion, it is a worthy carpooling mode to be extended in China.
\end{abstract}

\section{Introduction}

In China, some growing problems have constrained the development of urban transport and society, which include the crowded city population, the substantial increase of private cars, the urban road congestion, and the traffic pollution [1-3]. According to the data from 2000 to 2012, the private car ownership increased from 6.25 million to 88.38 million. The annual average growth rate was about $122.60 \%$. However, the road mileage increased from 1679.90 thousand kilometers to 4234.50 thousand kilometers. The annual average growth rate was about $107.37 \%$. The road construction is hard to meet the traffic demand. See Figure 1.

Traffic congestion, environmental pollution, energy shortages, taxi difficulties, and other issues cause people to begin exploring new and green private car trip modes [4]. A survey shows that there is only one person in $80 \%$ of private cars by highway gate during the morning peak hours in Beijing. Such trip efficiency apparently brought great pressure to traffic and environment and caused serious waste of transportation resources [5]. Carpooling will reduce about 400 thousand cars traveling every day in Beijing. Also, the automobile exhaust is causing serious effect on urban environment, and carpooling can reduce the emission of nitrogen oxides and the greenhouse gas (GHG). Besides, just like bus, regular carpooling is an effective way to encourage public transportation.

Since the high private car ownership with high emptyloading rate wastes huge traffic resources and moreover causes serious traffic congestion and exhaust emission pollution, research on green and economical trip mode is imperative [6]. The paper studies green traffic development of regional central city and puts forward the green transportation development strategy of commuting carpooling based on fixed time and routes innovatively. It is supported by Ministry of Housing and Urban Rural Development project Study on the Green Transportation Development Strategy in Regional Central City. By means of the opportunity of constructing Huai'an as the central city in northern Jiangsu, it takes Huaian as the pilot to design and realize the program. This is a theory and practice innovation attempt of green transport development. 


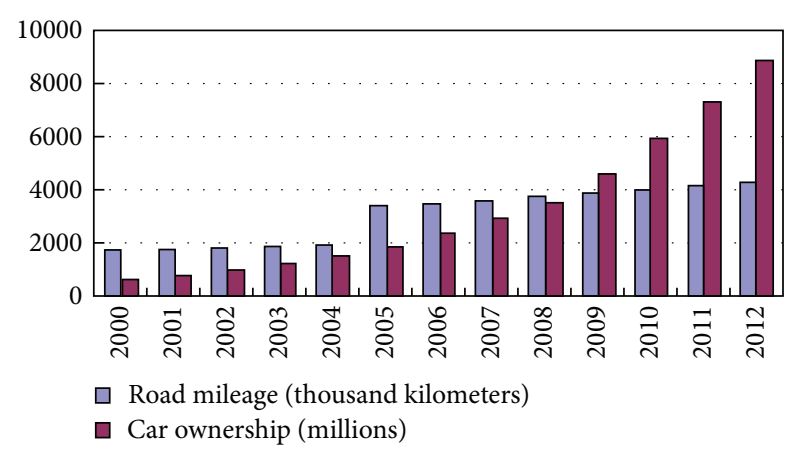

FIgure 1: The road mileage and private car ownership in China, 2000-2012.

\section{Related Work}

Carpooling has been attempted in different forms worldwide. It is relatively mature in Europe and America, where it has become a normal lifestyle $[7,8]$. The most representative system is the high occupancy vehicle (HOV) in California, which provides carpooling cars with dedicated lanes [9]. Now, private carpooling in China is in the exploratory stage. Though many cities have tried it, the effects are not ideal because of irrational organization.

Moni Naor proposed the fairness problem of carpooling in "On Fairness in the Carpool Problem." In order to insure sustainable carpooling, organizers should allocate some regular round-trip participants to the drivers. Furthermore, the concept of a fair share for the participants (FrankWilliams share) was defined. And a fair share of axiomatic characteristics to implement carpooling was provided [10].

In "A Cloud Computing Framework for Real-Time Carpooling Services," Zhang et al. put forward a carpooling service based on cloud computing [11]. It proposes that using computer client and mobile client through cloud computing to carpool could increase the efficiency of carpooling.

However, the development of carpooling is not smoothly in China [12]. One of the main works of research is legitimacy of carpooling. In "Tied Bus-Taking with Consideration," the author made analysis on legitimacy. The paper thought that carpooling is different from unlicensed cars for the compensatory payment is lower than drivers' expenses [13].

From existing research, there is no researcher involved in commute carpooling on fixed time and routes yet. This paper will study the commute carpooling based on fixed time and routes.

\section{Design of Commute Carpooling Based on Fixed Time and Routes}

3.1. Design of Carpooling Process. The fixed time and routes carpooling can be operated and managed by a pure public welfare or part-public welfare and part-profit company, which could be founded and supervised by the local transportation management office. The company's primary task is building information platform for fixed time and routes carpooling, which is the basis for connecting both sides of carpooling.
Also, the company is responsible for checking the effectiveness and legitimacy of the information of drivers and passengers. Besides, it is necessary to focus on those participants with illegal violation and bad credit history. Those serious cases can be directly rejected to join the carpooling system, in order to ensure the security, efficiency, and economy of the carpooling. In addition, all the personal information is invisible. The information which is accepted or rejected will be sent to users through the information platform directly.

The carpooling process is shown in Figure 2. Drivers register or login in the information platform and release the carpooling information of running time, location, and routes. Passengers register, login in, and submit the carpooling application with trip time, location, and routes information. Then, the information platform summarizes, checks, and matches all the information from drivers and passengers. Once successful, the system will send matched results to participants by computer and mobile client automatically. If participants are satisfied with matched results, the carpooling will be implemented on time. Otherwise, system must match the information circularly. Drivers or passengers can also directly select each other according to the information displayed without automatic matching by system. Participants will feedback their selections to the system. After completing, both sides of carpooling will make mutual evaluation on the platform. In order to improve the convenience of carpooling and mutual evaluation, the mobile APP software can be developed later so as to improve dynamic real-time carpooling information updates.

3.2. Design of Carpooling Information Platform. The information platform needs to support carpooling information from participants, as well as routes and time selection. Visualization operations by users, including user login, identity authentication, order management, and other functions are mainly realized by the Presentation Layer. Mutual selection and information matching are mainly processed by the Logical Layer. The Data Access Layer shows the progress of data dealing. The structure of the carpooling information platform is shown in Figure 3.

3.2.1. Function Design of Carpooling Information Platform. Information platform on fixed time and routes carpooling can use cloud storage and retrieval service. Functions of the platform mainly include information retrieval, information matching, mutual selection, and mutual evaluation.

The specific functions are the following.

(i) Information Retrieval. Drivers access the information platform, release carpooling information such as vehicle running time and routes, and query the passenger information. Passengers login the system, submit carpooling applications, namely trip time, location, and routes information, and check the driver information.

(ii) Information Matching. The information system summarizes drivers' time, routes information, and passengers' carpooling demand information and matches them reasonably. Then the matching results will be fed 


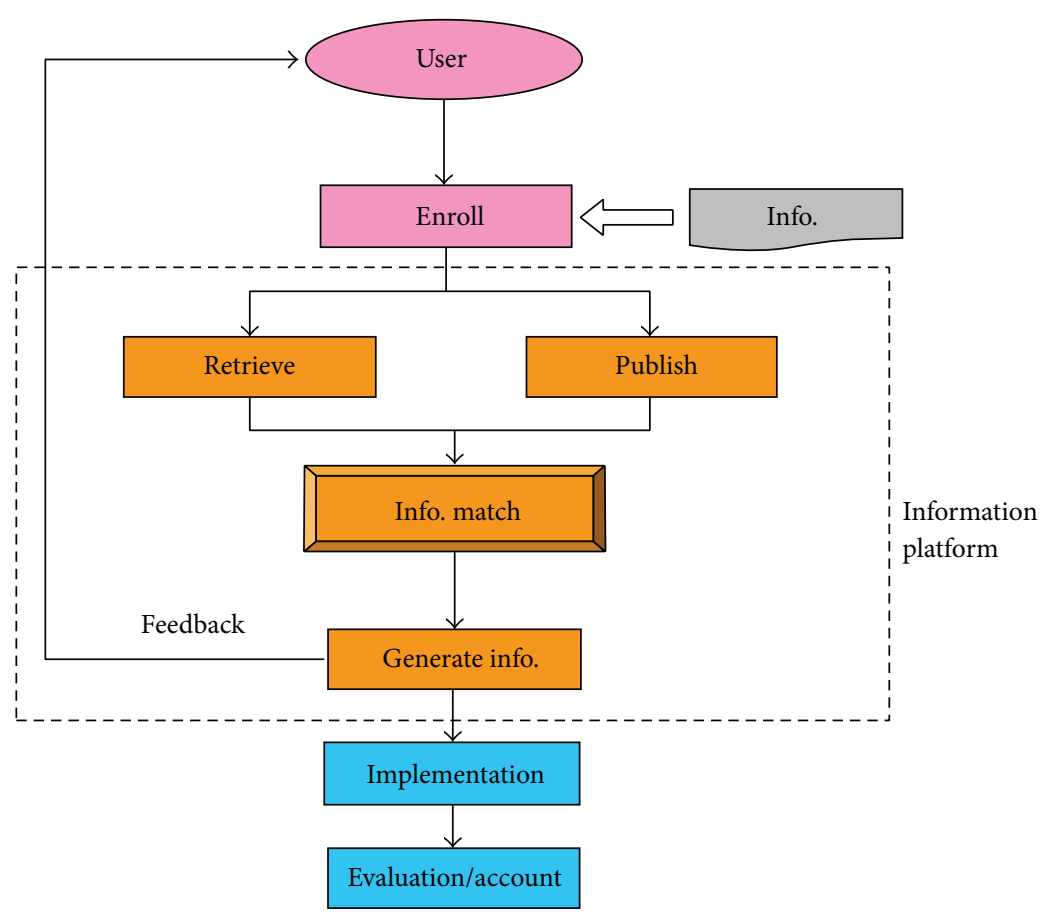

FIgURE 2: The flowchart of fixed time and routes carpooling.

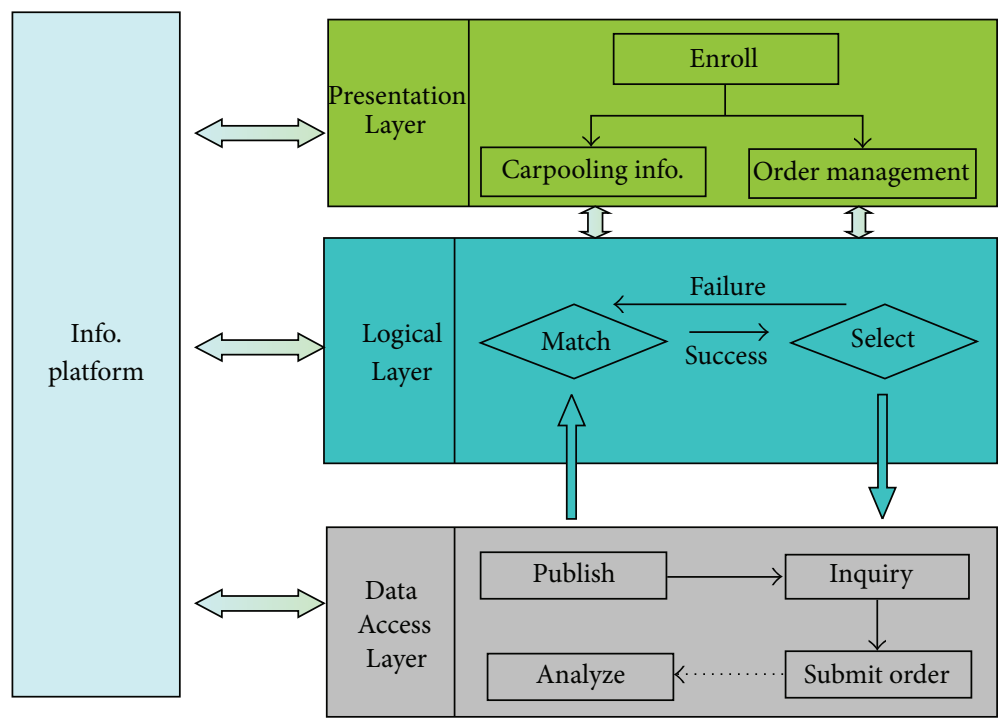

FIGURE 3: The structure of carpooling information platform.

back to both sides in time so as to complete the next step.

(iii) Mutual Selection. Drivers (passengers) select passengers (drivers) according to their own requirements and the initial matching information; if they select each other, then the matching will be successful. Otherwise, the system will continue matching information. The carpooling information will be processed by the platform once released by both sides. The system will send the matching information to drivers and passengers for mutual selection. Passengers judge the driver's driving ability and the vehicle condition. Drivers check the number of passengers, the working place, and time. If satisfying mutual selection cannot be reached, the system will match information again until both sides are satisfied with the matching results so as to realize the humanized carpooling and improve the carpooling efficiency.

(iv) Mutual Evaluation. The drivers and passengers will make mutual evaluation on the completed trip. The evaluation results will be recorded as personal credibility directly, which will affect the success rate of next 

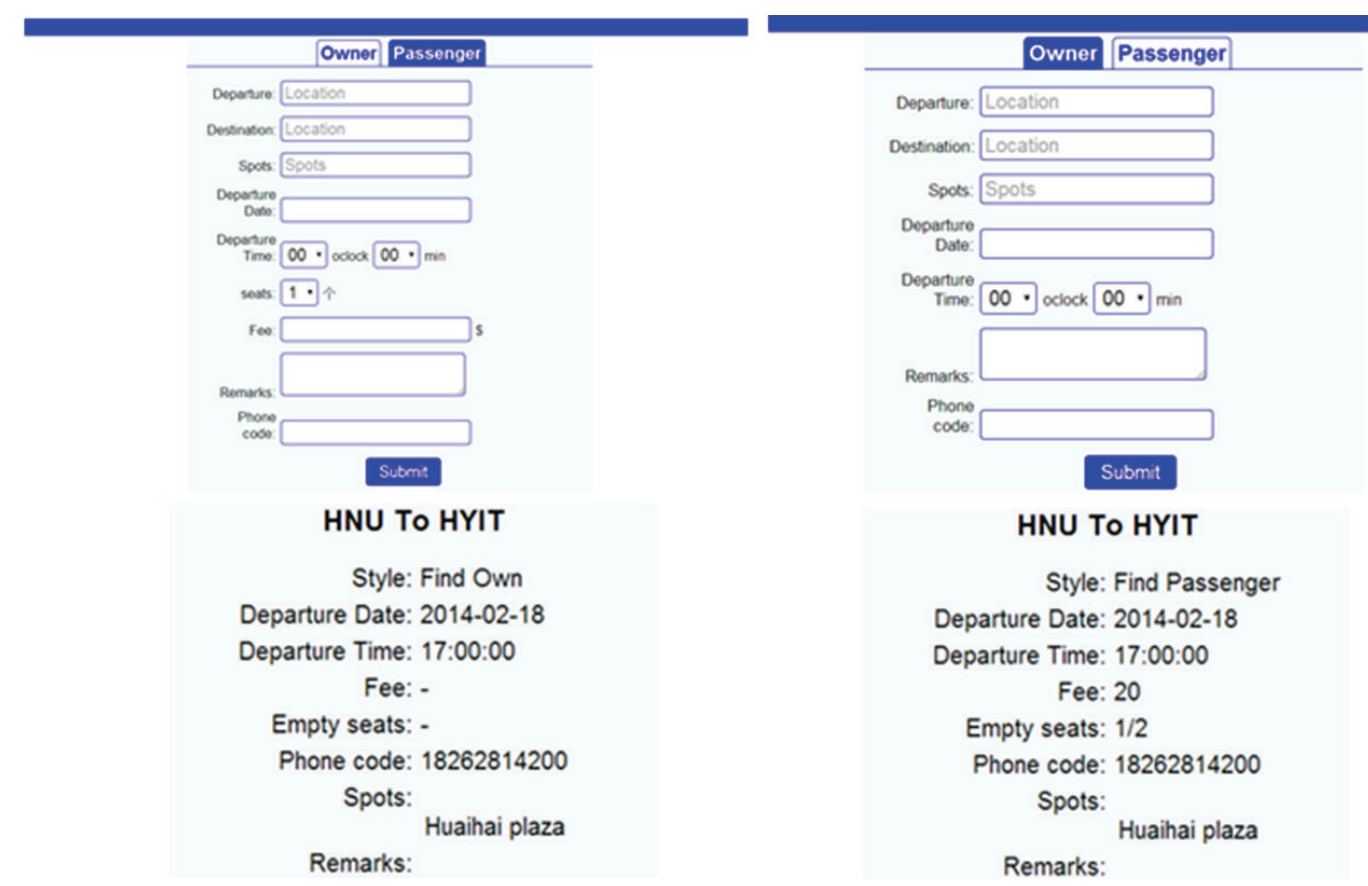

FIGURE 4: The main interfaces of carpooling system.

carpooling. For drivers, bad reputation will seldom make people willing to take their cars, thus affecting carpooling income. For passengers, bad credit will cause drivers reluctant to carpool with them and then greatly affect their commute convenience and economy. Mutual evaluation can be made through the mobile client anywhere [14].

3.2.2. Design of the Presentation Layer of Information Platform. Currently, relying on the Transportation Research Institute of Huaiyin Institute of Technology, Jiangsu, the carpooling program has established the fixed time and routes information platform [15]. The main interfaces of the platform are shown in Figure 4.

3.2.3. Design of the Business Logical Layer of Information Platform. Information matching is the key step during the designing of business Logical Layer. The results can be fed back to both sides of carpooling for confirming the selection timely only with rapid and effective information matching. Therefore, the paper constructed a mathematical model for information matching. The specific mathematical model is as follows:

IF $P\left(d_{k}, t_{l}\right) \subseteq O\left(d_{i}, t_{j}\right)$, THEN information matching succeeds;

IF $P\left(d_{k}, t_{l}\right) \not \subset O\left(d_{i}, t_{j}\right)$, THEN information matching fails;

$O\left(d_{i}, t_{j}\right)$ : the drivers' time set corresponding to going through certain site

$$
i, j-1,2,3, \ldots \text {; }
$$

$P\left(d_{k}, t_{l}\right)$ : the passengers' origins and destinations and corresponding time set

$$
l, k-1,2,3, \ldots
$$

The system will output the matching results directly when the passengers' routes and time accord with the drivers' information and then wait for the mutual selection by drivers and passengers.

\section{Experiment}

The experiment was carried out in Huai'an, China. It made detailed regulations on various aspects, which include market survey, carpooling time, and routes selection, formulating expense, checking vehicles and drivers, supervising carpooling, and fee settlement, to ensure the safety and economy of commute carpooling. In the following, evaluations on experiment results of part areas in Huaian will be conducted from two aspects: the time-expense and the entire network.

4.1. The Comprehensive Evaluation of Time and Expense. Considering double indexes of time and expense, ordinary traffic impedance model cannot analyze the carpooling program accurately and need to be improved. We put forward an improved time-expense traffic impedance model to evaluate it

$$
Q=a * T+E
$$

Q-The time-expense impedance;

$T$-Carpooling time (h); 
TABLE 1: The average time-expense impedance of multiple trip modes.

\begin{tabular}{lcccc}
\hline Trip mode & Bus & Private car & Taxi & Carpooling \\
\hline Time (h) & 0.35 & 0.18 & 0.19 & 0.20 \\
Expense (Yuan) & 2.00 & 11.57 & 26.00 & 2.50 \\
Traffic impendance (Q) & 1.02 & 0.40 & 1.06 & 0.14 \\
\hline
\end{tabular}

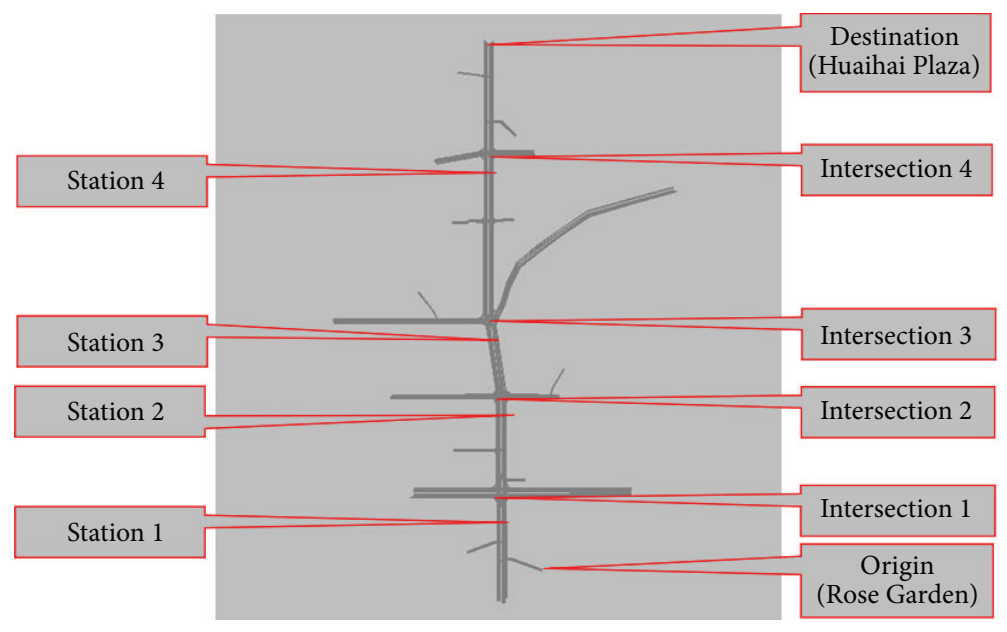

FIgURE 5: Simulation diagram of South Huaihai Road.

\section{E-Carpooling expense ( $¥)$; \\ a-Preference coefficient, 1.02 .}

The traffic impedance $(Q)$ is obtained by summing the traffic expense and weighted time. It is necessary to multiply time by the preference coefficient. After collecting and analyzing the preferable selection of citizens about travel burden, the time overweighs the expense and the result of preference coefficient is 1.02, which means people consider time more than the expense.

For the different dimensions and dimensional units in the expression, it is necessary to normalize the data. By comprising, Min-Max standardization is selected to normalize them to $[0,1]$. Following is the transition function:

$$
x_{k}=\frac{x-x_{\min }}{x_{\max }-x_{\min }} .
$$

Among them, $x$ is the sample data; $x_{k}$ is the normalized sample data; $x_{\min }$ is the minimum of sample data; $x_{\max }$ is the maximum of sample data.

One relatively mature route during the experiment was chosen to analyze, which is South Huaihai Road from Rose Garden to Huaihai Plaza. Most of people in Rose Garden are commuters, and twenty percentage of them own private cars. Huaihai Plaza is located at the center of Huai'an city, and it is the intersection of the main roads, as well as the necessary path for most of commuters. The original data obtained by investigating was comparatively analyzed among multiple transportation modes, then normalized and used for (3). The results are shown as Table 1.

Table 1 shows that the time-expense impedance of carpooling is the lowest, followed by private car, then bus, and

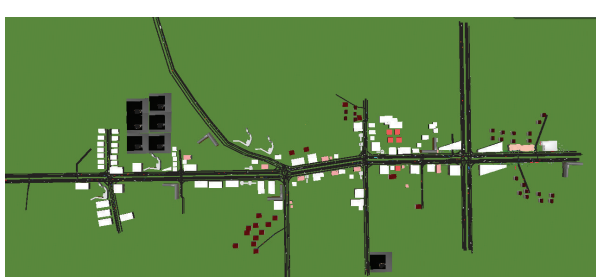

FiguRE 6: Simulation running diagram.

taxi. The impedance of taxi and bus is 7 times as much as carpooling, and private car is about 3 times. Carpooling can reduce $65 \% \sim 86 \%$ of the traffic impedance. It is easy to conclude that people will be forced to take private cars rather than bus or taxi if they have no chance to carpool. If possible, people will give priority to carpooling for short trip time and low cost. Therefore, compared with bus, taxi, and private car, carpooling has obvious advantages on saving time and trip expense greatly.

4.2. Evaluation of Road Network. The representative network of South Huaihai Road from Rose Garden to Huaihai Plaza was analyzed by VISSIM simulation system. We establish the VISSIM simulation model according to the actual situation of the network (shown in Figures 5 and 6), collect sufficient data (shown in Tables 2, 3, 4, 5, 6, 7, 8, 9, and 10), and adjust the simulation (shown in Table 11) in order to ensure the effectiveness of simulation. The study had compared the output data after carpooling from simulation system with the investigated data, which include average speed, average delay 
TABLE 2: The traffic input flow of roads.

\begin{tabular}{llcc}
\hline Road name & Lane type & Input flow $(\mathrm{veh} / \mathrm{h})($ motor vehicle) & Input flow (veh/h) (nonmotor vehicle) \\
\hline South Huaihai Road & Motor lane & 1000 & 1200 \\
East Jiefang Road & Motor lane & 700 & 800 \\
West Jiefang Road & Motor lane & 700 & 800 \\
Huaishu Road & Mixed lane & 100 & 100 \\
East Xinmin Road & Motor lane & 325 & 650 \\
West Xinmin Road & Motor lane & 320 & 650 \\
East Huancheng Road & Motor lane & 500 & 600 \\
West Huancheng Road & Motor lane & 375 & 450 \\
East Street & Motor lane & 296 & 600 \\
West Street & Motor lane & 320 veh/h & 600 \\
\hline
\end{tabular}

TABLE 3: The average time-expense impedance of multiple trip modes.

\begin{tabular}{lcccc}
\hline Phase & Red/yellow & Yellow & End of the red light & End of the green light \\
\hline 1 (South-North-Straight) & 0 & 3 & 3 & 33 \\
2 (South-North-Left) & 0 & 3 & 36 & 63 \\
3 (East-West-Straight) & 0 & 3 & 66 & 93 \\
4 (East-West-Left) & 0 & 3 & 96 & 116 \\
\hline
\end{tabular}

TABLE 4: Signal timing of South Huaihai Road and Xinmin Road intersection.

\begin{tabular}{lcccc}
\hline Phase & Red/yellow & Yellow & End of the red light & End of the green light \\
\hline 1 (South-North-Straight) & 0 & 3 & 3 & 43 \\
2 (South-North-Left) & 0 & 3 & 46 & 61 \\
3 (East-West-Straight-Left) & 0 & 3 & 64 & 79 \\
\hline
\end{tabular}

TABLE 5: Signal timing of South Huaihai Road and Huancheng Road intersection.

\begin{tabular}{lcccc}
\hline Phase & Red/yellow & Yellow & End of the red light & End of the green light \\
\hline 1 (South-North-Straight) & 0 & 3 & 3 & 36 \\
2 (South-North-Left) & 0 & 3 & 39 & 52 \\
3 (East-West-Straight-Left) & 0 & 3 & 55 & 84 \\
\hline
\end{tabular}

TABLE 6: Signal timing of South Huaihai Road and East-West Street intersection.

\begin{tabular}{lccccc}
\hline Phase & Red/yellow & Yellow & End of the red light & End of the green light & Cycle \\
\hline 1 (South-North-Straight) & 0 & 3 & 3 & 37 & 57 \\
2 (South-North-Left) & 0 & 3 & 40 & 60 & 79 \\
3 (East-West-Straight-Left) & 0 & 3 & 79 \\
\hline
\end{tabular}

TABLE 7: The path decision proportion of intersections (Left : Straight: Right).

\begin{tabular}{lccc}
\hline Name & South $\rightarrow$ North & North $\rightarrow$ South & East $\rightarrow$ West \\
\hline $\begin{array}{l}\text { Intersection of Huaihai } \\
\text { Road and Jiefang Road }\end{array}$ & $2: 6: 3$ & $2: 5: 3$ & $3: 4: 3$ \\
$\begin{array}{l}\text { Jiefang Road } \\
\text { Intersection of Huaihai }\end{array}$ & $1: 3: 1$ & $2: 5: 3$ & $1: 1: 1$ \\
$\begin{array}{l}\text { Road and Xinmin Road } \\
\text { XinMin Road }\end{array}$ & $1: 2: 2$ & & $3: 2: 6$ \\
$\begin{array}{l}\text { Intersection of Huaihai } \\
\text { Road and Huanchegn Road }\end{array}$ & $1: 6: 1$ & $3: 5: 2$ & $5: 2: 4$ \\
$\begin{array}{l}\text { Huancheng Road } \\
\text { Intersection of Huaihai } \\
\text { Road and East-West Street } \\
\text { East-West Street }\end{array}$ & & $1: 3: 1$ & $2: 2: 1$ \\
\hline
\end{tabular}




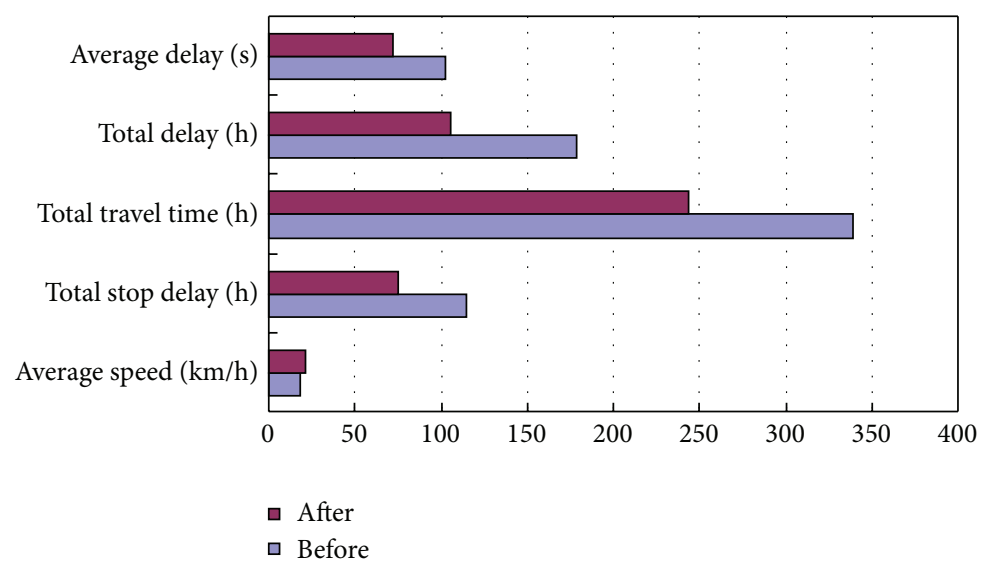

FIGURE 7: The comparison chart of simulation results before and after carpooling.

TABLE 8: Traffic flow composition.

\begin{tabular}{lcc}
\hline Section & Traffic composition & Proportion \\
\hline Huaihai Road, Jiefang Road, Xinin Road, and Huancheng Road & Private car/large vehicle & $97 / 3$ \\
All nonmotorized vehicle lanes & Bicycle/pedestrian & $13 / 7$ \\
Huaishu Road & Car/bicycle/pedestrian & $25 / 12 / 5$ \\
East-West Street & Car & 1 \\
\hline
\end{tabular}

TABLE 9: Width of lanes.

\begin{tabular}{lccc}
\hline Lane type & Motor lane & Nonmotorized vehicle lane & Mixed lane \\
\hline Width (unit: meter) & 3.5 & 4.0 & 3.5 \\
\hline
\end{tabular}

TABLE 10: Number of lanes (bidirectional).

\begin{tabular}{lcccccc}
\hline Name & South Huaihai Road & Jiefang Road & Huaishu Road & Xinmin Road & Huancheng Road & East-West Street \\
\hline Number of lanes & 6 & 6 & 2 & 2 & 2 \\
\hline
\end{tabular}

TABLE 11: The comparison of speed.

\begin{tabular}{lccr}
\hline Direction & Surveyed speed $(\mathrm{km} / \mathrm{h})$ & Emulational speed $(\mathrm{km} / \mathrm{h})$ & \\
\hline South & 37.0 & 36.1 & $2.4 \%$ \\
North & 37.0 & 36.0 & $2.7 \%$ \\
East & 37.5 & 38.5 & $2.7 \%$ \\
West & 37.5 & 36.5 & $2.7 \%$ \\
\hline
\end{tabular}

time, total travel time, total delay time, and total stopped delay (shown in Table 12 and Figure 7).

The simulation running diagram is shown in Figure 6.

The group members made investigation on the South Huaihai Road in April, 2014, to learn the basic operation status and collected necessary data of the network, which contains traffic input volume (see Table 2), intersection signal timing (see Tables 3-6), path decision proportion of intersections (see Table 7), traffic flow composition (see Table 8), lane width (see Table 9), and number of lanes (see Table 10). Then these data were input into the simulation system to check the model.
The survey data was inputted into the simulation model, and one of the intersections was chosen to do simulation test. Then the simulation results were compared with the actual survey data (see Table 11) for evaluating the accuracy and reliability of the simulation model.

Table 11 shows that the simulation errors are all controlled within $5 \%$. The simulation model has an ideal fitting with the reality and can be used for simulation experiments.

The running results are shown in Table 12.

Table 12 and Figure 7 show that after carpooling, the average speed rises $17.83 \%$, the total stopped delay decreases $34.84 \%$, the total travel time decreases $28.29 \%$, the total delay 
TABLE 12: Simulation results before and after carpooling.

\begin{tabular}{lcc}
\hline Evaluation index & Before & After \\
\hline $\begin{array}{l}\text { Average speed }(\mathrm{km} / \mathrm{h}), \\
\text { vehicle class car }\end{array}$ & 18.23 & 21.48 \\
$\begin{array}{l}\text { Total stopped delay }(\mathrm{h}), \\
\text { vehicle class car }\end{array}$ & 144.79 & 74.80 \\
$\begin{array}{l}\text { Total travel time (h), } \\
\text { vehicle class car }\end{array}$ & 339.33 & 243.35 \\
$\begin{array}{l}\text { Total delay time (h), vehicle } \\
\text { class car }\end{array}$ & 178.32 & 105.40 \\
$\begin{array}{l}\text { Average delay time per } \\
\text { vehicle, vehicle class car }\end{array}$ & 102.14 & 72.28 \\
\hline
\end{tabular}

time decreases $40.89 \%$, and the average delay time per vehicle decreases $29.23 \%$. From the simulation results, the network parameters were optimized up to $20 \% \sim 40 \%$ after carpooling, which greatly improved the traffic congestion of the network.

\section{Conclusion}

The study has designed commute carpooling program based on fixed time and routes, built the carpooling information platform, and realized functions including information retrieval, information matching, and mutual selection and mutual evaluation. Furthermore, it had built an improved traffic impedance evaluation model and a VISSIM simulation model to evaluate the effects of the program experimented in Huaian. The result shows that the design has reduced the time-expense impedance by $65 \% \sim 86 \%$ and optimized some network parameters up to $20 \% \sim 40 \%$, which have greatly reduced the trip time and cost, improved the security and economy of carpooling process, and eased the traffic congestion of network. This exploration on the fixed time and routes carpooling has also provided solid evidence and positive reference for China to liberate carpooling.

\section{Conflict of Interests}

The authors declare that there is no conflict of interests regarding the publication of this paper.

\section{Acknowledgments}

This research was supported by Basic Science Research Program through the National Natural Science Foundation of China (51308246). This research was supported by Graduate Innovative Projects of Jiangsu Province in 2014 (KYLX_1059). This research was supported by the Jiangsu Government Scholarship for Overseas Studies (Grant no. JS-2010-K002).

\section{References}

[1] D. Fuller, S. Sahlqvist, S. Cummins, and D. Ogilvie, "The impact of public transportation strikes on use of a bicycle share program in London: interrupted time series design," Preventive Medicine, vol. 54, no. 1, pp. 74-76, 2012.
[2] W. Wills and E. L. La Rovere, "Light vehicle energy efficiency programs and their impact on Brazilian $\mathrm{CO}_{2}$ emissions," Energy Policy, vol. 38, no. 11, pp. 6453-6462, 2010.

[3] L. Tartakovsky, V. Baibikov, J. Czerwinski et al., "In-vehicle particle air pollution and its mitigation," Atmospheric Environment, vol. 64, pp. 320-328, 2013.

[4] Y. Zhu, A. Eiguren-Fernandez, W. C. Hinds, and A. H. Miguel, "In-cabin commuter exposure to ultrafine particles on Los Angeles freeways," Environmental Science \& Technology, vol. 41, no. 7, pp. 2138-2145, 2007.

[5] Q. Zhang and Y. Zhu, "Performance of school bus retrofit systems: ultrafine particles and other vehicular pollutants," Environmental Science and Technology, vol. 45, no. 15, pp. 64756482, 2011.

[6] Y. Jiang, X. He, and X. Guo, "Discussion on the evaluation index system of urban green traffic planning," Journal of Hefei University of Technology (Natural Science), vol. 9, p. 012, 2008.

[7] T. Libiao, "Foreign carpooling scan," Traffic and Transportation, vol. 2011, no. 1, pp. 68-69, 2011.

[8] C. Wang, "Overview on carpooling of developed countries," Traffic and Transportation, no. 6, pp. 62-63, 2011.

[9] G. Zhou, "Problems and solutions on carpooling of private car," Transportation Standardization, vol. 23, pp. 4-7, 2013.

[10] D. Jianjun, "Evaluation of a resource-saving and environment friendly Urban transport system," Transport Information and Safety, vol. 31, no. 5, pp. 154-158, 2013.

[11] K. Zhang, J. Lu, and Y. Sun, "The design of an intelligent carpool-matching system based on LBS-Cloud service," Application of Electronic Technology, no. 8, pp. 20-22, 2013.

[12] R. Wang, "Shaping carpool policies under rapid motorization: the case of Chinese cities," Transport Policy, vol. 18, no. 4, pp. 631-635, 2011.

[13] C. Ying, "Study on law about 'car-pooling," Journal of North China University of Technology, vol. 21, no. 4, pp. 19-22, 2009.

[14] Z. Qinghe, "Design and implementation of mobile carpooling system based on web service," Geospatial Information, no. 4, pp. 85-87, 2013.

[15] Z. Guiliang, "Commuting carpooling system based on fixed time and route," Chinese Patent 2014SR036995, 2014. 

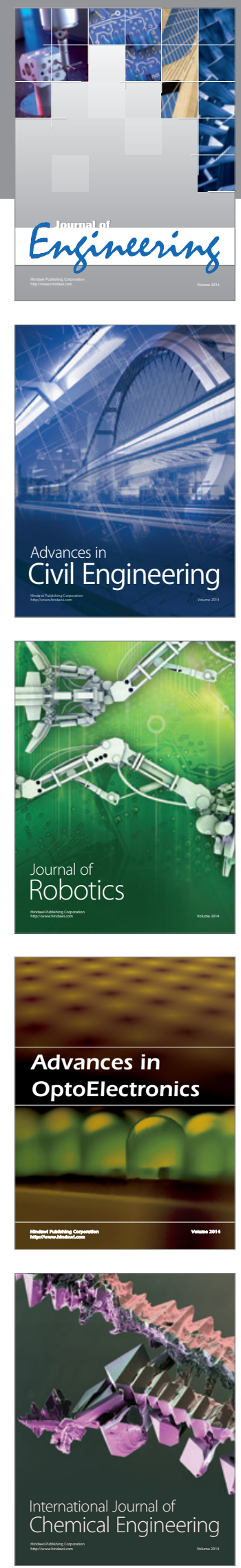

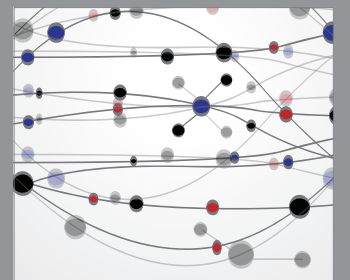

The Scientific World Journal
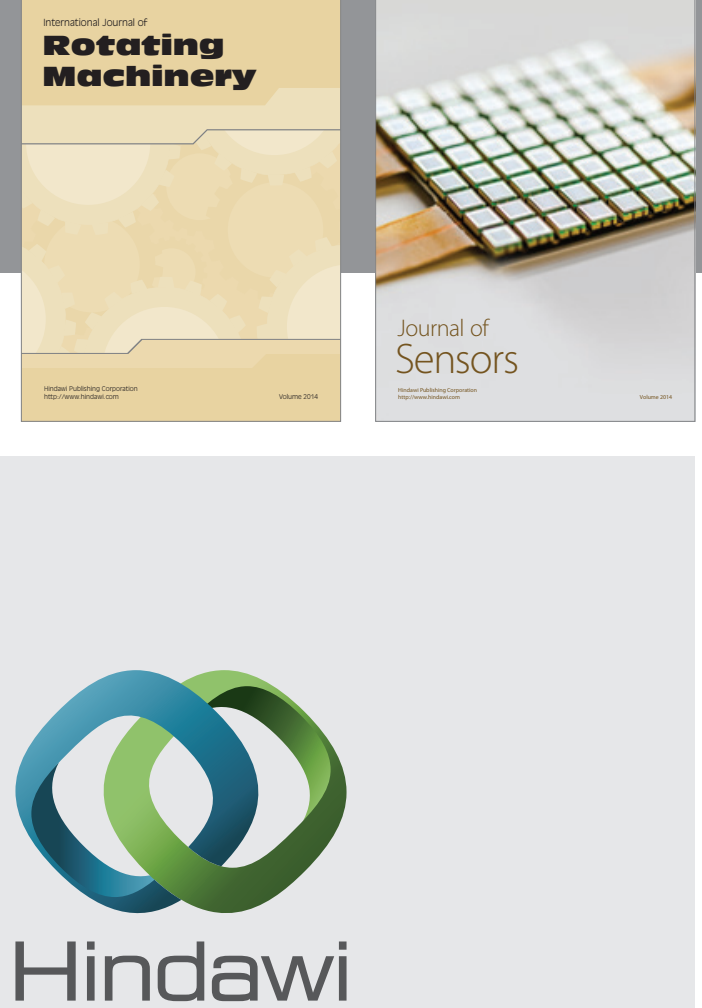

Submit your manuscripts at http://www.hindawi.com
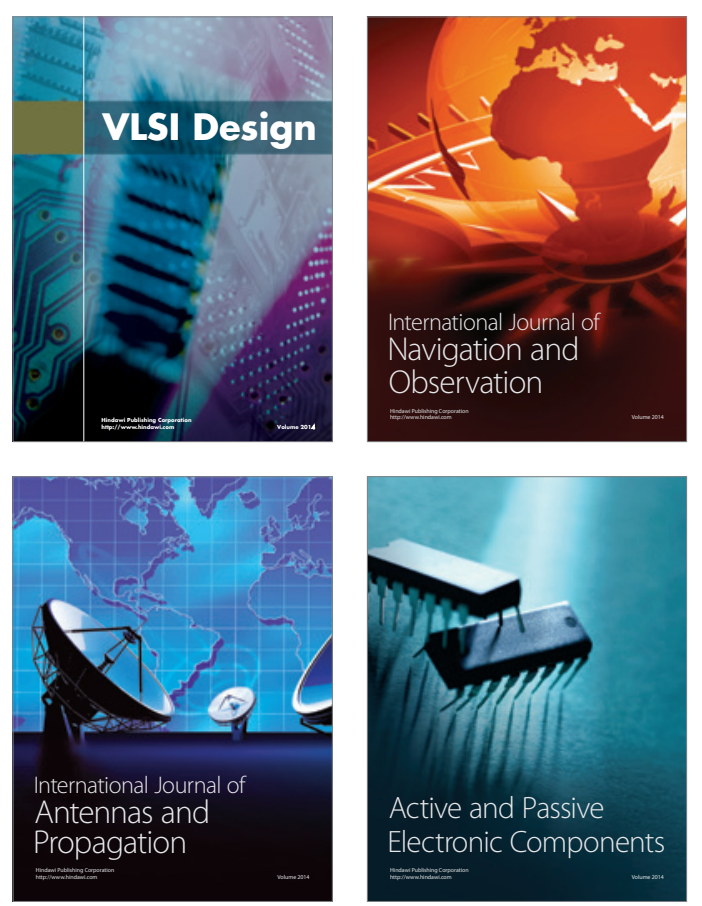
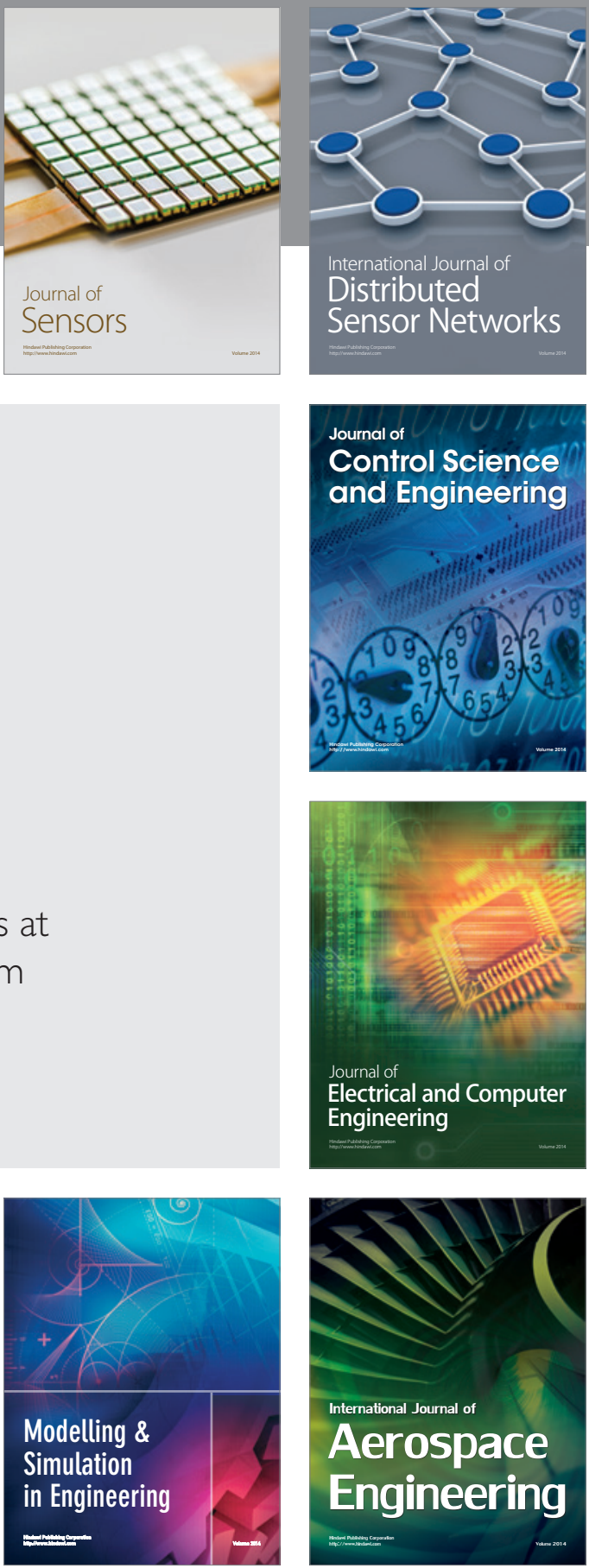

Journal of

Control Science

and Engineering
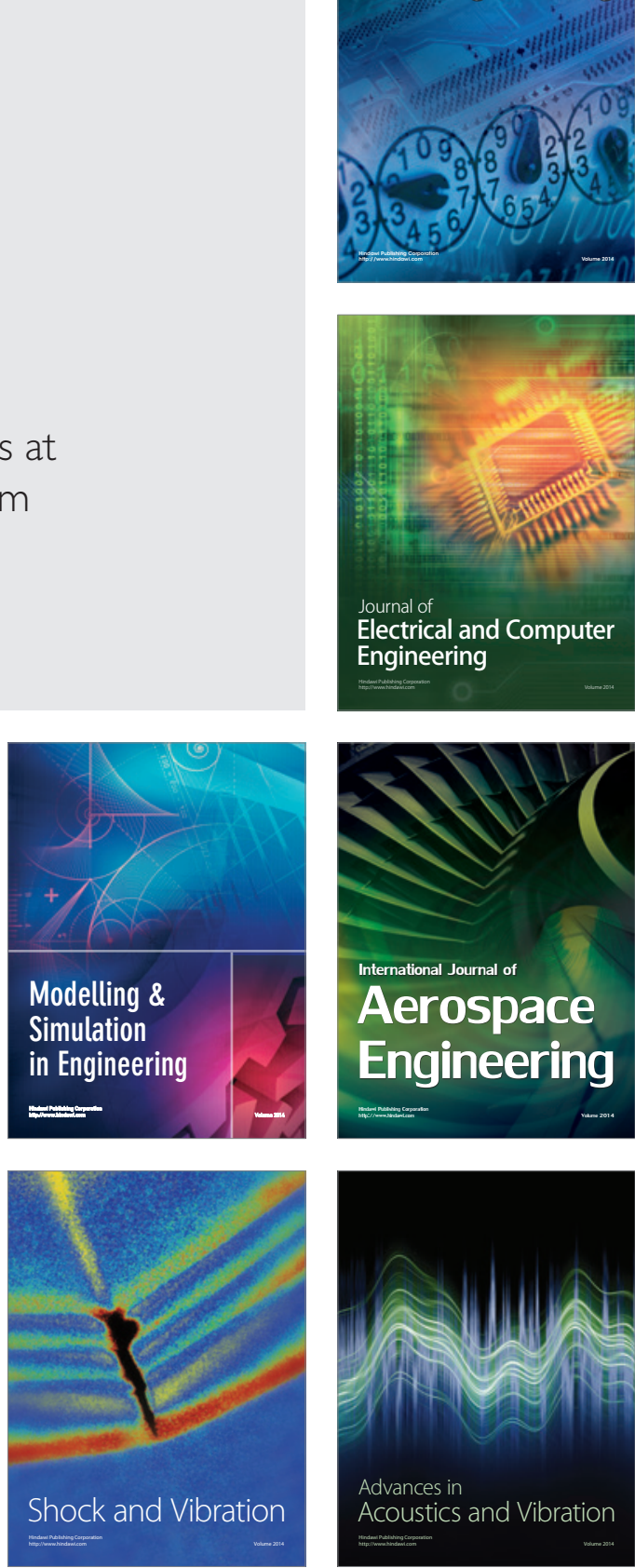